\title{
Tobacco use and concurrent engagement in other risk behaviours: A public health challenge for occupational therapists
}

\author{
Matumo Catherine Ramafikeng, BSc OT (UCT), MSc OT (UCT), PhD Education (UCT) \\ https://orcid.org/0000-0002-2989-1965 \\ Lecturer, Occupational Therapy Division, Health and Rehabiliation Sciences, Faculty of Health Sciences, University of Cape Town
}

Galvaan Roshan, BSc OT (UCT), MSc OT (UCT), PhD (UCT) https://orcid.org/0000-0003-00 I4-I842

Associate Professor, Occupational Therapy Division, Health and Rehabiliation Sciences, Faculty of Health Sciences, University of Cape Town

Seyi Ldele Amesun, BSc PT (UCT), PhD (UCT), PG Dip Health Professional Education https://orcid.org/0000-000I-7385-227X

Associate Professor, Physiotherapy Division, Health and Rehabiliation Sciences, Faculty of Health Sciences, University of Cape Town

Introduction: Occupational therapists are concerned about what people do and how that impacts their health and well-being. However, occupational therapy contributions to the cessation and prevention of tobacco use remain limited. Tobacco use constitutes occupational performance that poses a serious threat to health, well-being and quality of life. The purpose of this paper is to report the extent of tobacco use and discuss the nature of risk behaviours among high school learners in the city of Maseru, Lesotho.

Method: The paper draws on findings of a larger study that aimed to establish the prevalence of risk behaviours among high school learners in Lesotho. I I 2 I learners aged I2-27 years completed the Lesotho Youth Risk Behaviour Survey (LYRBS) in a school-based cross-sectional survey. STATA and Microsoft Excel we used for data analysis.

Results: The findings highlight the co-occurring and concurrent nature of risk behaviours, such as use of other substances, gambling and sexual behaviours with tobacco use dominating clusters of concurrent engagement.

Conclusion: Tobacco use is an occupation and a public health emergency that requires urgent attention from an early age. Delaying early initiation of tobacco use could prevent engagement in other risk behaviours thereby avoiding associated health consequences. With their understanding of occupation, occupational therapists can contribute immensely to interventions aimed at curbing engagement in risk behaviours.

Key words: Health risk behaviours; Youth; Occupational performance; Lesotho Youth Risk Behaviour Survey (LYRBS); concurrent behaviours

\section{INTRODUCTION}

Tobacco use is defined as any habitual use of the tobacco plant leaf and its products through inhalation, sniffing, sucking and chewing'. Tobacco use predominantly starts in adolescent years ${ }^{2}$ as a drug of initiation ${ }^{3}$. Hence, the prevalence of tobacco use tends to be higher among adolescents than other age groups ${ }^{4}$.

Using tobacco forms part of the occupational repertoire of many people. This is despite knowledge of the long-term negative consequences of engagement for the users and those around them. Within the occupational repertoire of many youth, including learners, there are activities which promote their health and activities that may put them at risk of ill health. Activities that expose youth to the risk of ill-health are classified as health risk behaviours and they include sexual intercourse, tobacco use, alcohol consumption, violent behaviours and taking illicit drugs ${ }^{5}$. Literature that explores risk behaviours from an occupational perspective is scarce. Activities [and risk behaviours] associated specifically with addiction have been found to meet the criteria for occupation and tobacco use was only recently acknowledged in occupational therapy and science literature as an occupation ${ }^{6}$. Hence the continuing need for further research on this health-risk behaviour from an occupational perspective. The aim of the study was to establish the prevalence of risk behaviours among the youth who are high school learners in the city of Maseru, Lesotho.

The objectives focused on different health risk behaviours. These were:

$*$ To establish the socio-demographic profile of high school learners who engage in health risk behaviours in schools in the city of Maseru.

$*$ To determine the proportion of learners who engage in risk behaviours related to personal safety.

* To determine the proportion of learners who engage in violence-related behaviours.

$*$ To determine the proportion of learners who express feelings of sadness or have attempted suicide.

$\downarrow$ To determine the proportion of learners who engage in tobacco use.

$\rightarrow$ To determine the proportion of learners who use alcohol.

* To determine the proportion of learners who use illicit drugs.

* To determine the proportion of learners who engage in sexual behaviours.

* To determine the proportion of learners who engage in physical activity.

* To establish relationships between different groups of learners within and across categories. 


\section{LITERATURE REVIEW}

\section{An occupational perspective of tobacco use}

Adopting an occupational perspective to tobacco use is useful as it highlights that tobacco use is a concern within the scope of practice for occupational therapy. Tobacco use constitutes occupational performance that predominantly puts the user at risk of ill health. Although, tobacco use is classified as a risk behaviour, it can also be considered as occupational performance as it constitutes 'active doing and accomplishing an action, skill, activity or occupation that is important to a person as a result of a transaction between the person, context and activity'7. Tobacco use also has a negative impact on other occupational performance areas, such as learning.

For instance, among children and adolescents, learning is one of the areas mostly affected by tobacco use. A study based in India demonstrated a strong association between tobacco use and poor academic performance ${ }^{8}$. The negative impact of tobacco on cognitive functioning is not only experienced by the user, but by those exposed to second-hand smoke, particularly children and adolescents. A systematic review of literature seeking to establish the relationship between exposure to second-hand smoke and the cognitive functioning in young children and adolescents found that postnatal passive smoking was associated with poor cognitive functioning and poor performance on academic tests ${ }^{9}$. A similar finding emanated from a study conducted to explore cognitive function and family life among 6-12 year old elementary school children in Jordan, where a decrease in cognitive functioning among children that lived in rural areas and had a parent that smoked was reported ${ }^{10}$. Cognitive performance is not the only area affected by tobacco use.

Tobacco use was also found to negatively impact performance of physical activities. In a study among US Navy male personnel, smokers were found to have less physical endurance and a lower body mass index (BMI) than non-smokers ${ }^{\prime \prime}$. Over a 4-year period, the rate of cardio-respiratory fitness had decreased at a significantly greater rate resulting in a reduced ability to perform physical activities.

Using tobacco presents a challenge to occupational therapists as it is widely accepted in the profession that meaningful and purposeful occupations promote health and well-being. Wilcock ${ }^{12: 139}$ indicated that "if well-being is to be attained, doing needs to provide meaning and purpose". However, Luck et al ${ }^{13: 2}$ indicate that occupations like tobacco use "may also be meaningful, purposeful, engaging, enjoyable, and connected to well-being" for the individual and collective. The consequences of tobacco use seem two-fold, but emphasis is often on the negative consequences given their potential to be life threatening.

\section{Consequences of tobacco use}

Tobacco use is an example of an occupation that has both positive and negative consequences. An occupation in itself is neither healthy nor unhealthy ${ }^{6}$, but the outcome of engagement in an occupation can be characterised as such. In this paper, the consequences of tobacco use are categorised as socio-cultural, physical and psychological or psychiatric in nature. The socio-cultural effects of tobacco use tend to have a positive impact on well-being as discussed in the section below. However, the physical, psychological or psychiatric and economic impacts of participation in the occupation are negative and have long term consequences as will be outlined below. This highlights the complexity of the relationship between health and well-being ${ }^{13}$.

\section{Socio-cultural benefits}

Some positive socio-cultural effects of tobacco use include promoting acculturation, identity development and a sense of belonging, when it forms part of the lifestyle of a group. Tobacco use in the form of smoking is a significant part of the Yup'ik from southwest Alaska's lifestyle and members who smoked were reported to display greater acculturation than non-smokers or those who engaged in other forms of tobacco use ${ }^{14}$. In this case smoking is used as a mechanism for socialisation.

Tobacco is also used as part of rites of passage into adulthood or as a signifier of membership to a specific group. In a study among learners aged I4-15 year in two schools in Stockholm, smoking was regarded as a symbol of adult life ${ }^{15}$. In a study of teenage subcultures and their role in shaping attitudes, use of substances; tobacco and alcohol were identified as recognisable markers of members of counter-subcultures ${ }^{16}$. In this regard, tobacco use fostered a sense of belonging and it was enacted as a shared occupation. For example, Stjerna et al ${ }^{15: 577}$ show that smoking, as a predominant form of tobacco use "is sometimes described as part of teenage lifestyle; such as being together with friends, 'going out' and enjoying oneself". The same sense of belonging derived from smoking with others was also reported by adult females ${ }^{13}$.

\section{Physical consequences}

The use of tobacco tends to continue through adulthood to old age, often with adverse and life-threatening consequences. There is an abundance of evidence showing physical negative effects of tobacco use amongst different groups and societies. Tobacco use has been reported to account for deaths of about 6 million people globally on an annual basis and these may increase to an estimated 8 million per year by $2030^{17}$. This amounts to more deaths than those associated with HIV/AIDS, TB and malaria combined ${ }^{18}$. Smoking in particular has been identified as a risk factor for cancer ${ }^{19}$, atherosclerosis ${ }^{20}$, and oral ailments such as teeth loss and halitosis among others ${ }^{21}$. It has also been categorised as one of the leading causes of coronary heart disease ${ }^{22}$. These consequences are likely to impede daily function and social interaction, therefore affecting well-being and quality of life.

\section{Psychiatric consequences}

Smoking has been strongly associated with psychiatric illnesses, although the nature of the association may differ. In a study conducted by Husky et $\mathrm{a}^{23: 178}$, among 43093 young adults, "prior, occasional, and daily smoking were found to statistically increase the odds of presenting with current and lifetime major depression". This form of tobacco use was also associated with an increased risk of developing panic attacks and panic disorder in young adults ${ }^{24}$. The relationship between anxiety and depression and smoking seems to be interdependent. Extensive research has been conducted that shows that anxiety and depressive symptoms were more likely to be reported by smokers than non-smokers and that those with preexisting symptoms were also more likely to smoke $\mathrm{e}^{25-27}$. A study in the Netherlands explored the association between age of initiation of smoking and age of onset of depression and anxiety disorders and the findings indicated that smokers developed psychopathology within five years of starting smoking ${ }^{27}$, suggesting a causal relationship between smoking and depression and anxiety.

\section{Early onset}

Other than predisposing the individual to psychopathology, early initiation of tobacco use could precipitate engagement in other health risk behaviours. Smoking has been associated with the increased likelihood of alcohol and other substance use, therefore predisposing the individual to alcohol and drug dependence or abuse in adulthood ${ }^{28}$. Another risk behaviour that was associated with early onset of tobacco use was sexual behaviours, resulting in early pregnancy ${ }^{29}$. This association between risk behaviours suggests co-existence of risk behaviours.

Co-occurrence of multiple risk behaviours poses a bigger threat to health and well-being. There has been increasing research on multiple risk behaviour engagement and associated consequences. For example, a study conducted among homeless youth in Ghana established that the youth tend to engage in multiple risk behaviours associated with survival and participants exhibited psychological problems that were moderate to severe in nature ${ }^{30}$. Another study conducted among 12-18 year-old African American youth examined 
interdependent trajectories of risk behaviours such as sexual behaviours, substance use and conduct problems and consequences were mapped out according to the level of risk taking ${ }^{31}$. These studies present a challenge for single behaviour intervention strategies, as designing intervention for one risk behaviour negates the fact that risk behaviours tend to co- occur. In addition, "integrated prevention programs have been found to be more feasible and effective than discrete prevention strategies" $32: 19$.

Literature presented above supports the view that meaningful occupations could be detrimental to health. This realisation has led to a proposed review of the profession's shared assumptions that view engagement in occupations from a positive stance only ${ }^{33}$. This perception has perpetuated "marginalisation of those occupations that may be negative, problematic or detrimental to health" ${ }^{34: 7}$ as evident in the limited attention these occupations have received in literature ${ }^{34,35}$. This could explain why tobacco use has not been well documented in occupational therapy and occupational science literature.

The limited attention to the study of tobacco use as occupation could explain the lack of contributions by occupational therapists in prevention, curbing and cessation of tobacco use. As a result, the profession may be lagging behind in critical international public health conversations regarding the epidemic. This is despite the professions' commendable contribution in addressing other public health issues, such as obesity as shown in an integrative literature review that explored the role and evidence base of occupational therapy practice in obesity ${ }^{36}$. Such evidence suggests that occupational therapists have the knowledge and skills to draw intervention for other public health issues.

\section{METHOD}

This paper draws on findings of a larger study conducted in 2010. The aim of the study was to establish the prevalence of health risk behaviours among high school learners in the city of Maseru, Lesotho ${ }^{37}$. A study of this nature and magnitude had not been conducted in Lesotho. One of the objectives of the study was to determine the proportion of learners who engaged in tobacco use. The objective of this paper is to report on this objective and discuss the nature of risk behaviours, supporting the argument of a need for occupational therapy to contribute to intervention on tobacco use.

\section{Study Context}

Lesotho is landlocked by South Africa, with a population of about I, 8 million with $51.3 \%$ being between 5 and 29 years of age ${ }^{38}$. The official languages are Sesotho and English. Administratively the country is divided into ten districts; Maseru is both the largest district and the capital of Lesotho with $22.9 \%$ of the country's population ${ }^{39}$. These factors contributed to the decision to conduct this study in the city of Maseru and among youth.

The Lesotho school system managed by the Ministry of Education and Training is divided into five consecutive levels. The Early Childhood Care and Development level accommodating children between the ages of 3-5; primary, consisting of 7 levels with children starting at the age of 6 ; junior secondary comprising of 3 levels (Forms A-C); higher secondary with two levels (Form D \& E) and tertiary education ${ }^{39}$. The main proprietors or owners of schools are churches; the Anglican, Methodist, Roman Catholic and the Lesotho Evangelical. Other schools are owned by the government or communities ${ }^{40}$. Regardless of the proprietor, all schools are accountable to the Ministry and the majority are co-educational ${ }^{37}$.

A school-based cross-sectional survey was conducted using a self-administered questionnaire.

\section{Participants}

The study population comprised of all learners $(n=9726)$ in Forms $A, B, C, D$ and $E$ in co-educational high schools within a $10 \mathrm{~km}$ radius of the central business district of Maseru. Only schools that followed the school calendar set by the Ministry of Education and
Training were included. A total of 1769 learners from 7 schools were recruited for this study and II 2 I learners $(63,4 \%$ response rate) took part in the study. One questionnaire was excluded from analysis as it was $50 \%$ incomplete.

Of the II2I participants $50.1 \%(\mathrm{~N}=562)$ were female and $49.9 \%(N=559)$ were male. The majority of the sample were Lesotho citizens by birth $(93.6 \%, \mathrm{~N}=1049)$. Their age range was between 12 and 27 years. The mean age was 16 years with a standard deviation (sd) of 2.09 and a confidence interval $(\mathrm{Cl})$ of between 16.3 and 16.5. The age distribution of the sample reflected the typical profile for high school learners in Lesotho. For instance, learners in Form $A$ are often in the age bracket of $12-13$ years and those who progress through high school education successfully at each level often complete at age 16 or 17.

\section{Recruitment process}

Two stage sampling was employed to select both the schools and the participants, starting with cluster sampling and then random sampling. For selection of schools, 18 schools were clustered according to the proprietor. A representative school was then randomly selected from each cluster, resulting in six schools initially selected from the following proprietorship clusters: the Anglican, Lesotho Evangelical, Methodist, Roman Catholic and Seventh Day Adventist churches and the Government. However, the response rate from the Anglican school was lower than $50 \%$, therefore a second Anglican school was recruited.

Schools tend to have more than one class per level, due to the number of learners that apply to the schools. For example, Form A can have AI, A2, A3 and sometimes A4 with an average of about 50 learners per stream giving a total of 200 Form A learners. All the selected schools had more than one class per level. A class was then randomly selected to represent each Form adding up to a total of 5 randomly selected classes.

\section{Data collection}

The study instrument was an hour long paper-based, selfadministered questionnaire presented in English. The US Youth Risk Behaviour Surveillance System (US YRBSS) ${ }^{41}$ was adapted to develop the Lesotho Youth Risk Behaviour Survey (LYRBS) ${ }^{37}$. The validity and reliability of the USYRBSS had been previously established ${ }^{41}$. The Lesotho YRBS was designed to ensure clarity and contextual relevance. Phrases and specific terms for behaviours were changed to make it contextually relevant. This was tested in a pilot study; however, reliability and validity were not tested, because this involves an extensive and rigorous process that limitations in resources did not permit. After the pilot, questions were added and others modified. It is recommended that the tool be tested for reliability and validity in the future. The Lesotho YRBS was a 112 item long questionnaire divided as follows:

\section{* Section A: demographic information}

* Section B: questions about personal safety on the road

* Section C: violence-related behaviours

* Section D: questions on suicide

* Section E: tobacco use

* Section F: questions about drinking alcohol

* Section G: questions about matekoane ${ }^{a}$ use

* Section H: drug use

* Section I: sexual behaviour

* Section J: questions on body weight

* Section K: questions on physical activity

* Section L: nutrition.

The questionnaire was administered in English, because this is the language of instruction in high schools in Lesotho. This paper reports on section $E$, tobacco use (the questions from Section $E$ are attached as Appendix).

\footnotetext{
a Matekoane is the local name for dagga or cannabis
} 


\section{Data analysis}

Data analysis was conducted using STATA $10.0^{42}$. The process of analysis began with descriptive statistics such as frequencies and percentages which were relevant for establishing prevalence. The mean age of subjects, range and standard deviation were calculated to enable analysis using age and gender. To establish relationships between and across categories the Chi-square test was used. This analysis was compatible to that used in the USYRBSS and the South African YRBS. Conducting a similar analysis in this study would enable comparison with youth risk behaviours surveys conducted in other countries.

A selection of behaviours that participants reported was used to determine concurrent engagement in risk behaviours using Pivot tables in Microsoft Excel. The criteria for selection entailed behaviours participated in 30 days prior to data collection (data was collected in the first term of the school year), but not those that they were subjected to, such as being threatened or being driven

\section{Table I: List of risk behaviours that formed clusters}

\begin{tabular}{|c|c|}
\hline I. & Did not use seat belt when driven \\
\hline 2. & Did not use seat belt when driving \\
\hline 3. & Drove drunk \\
\hline 4. & Walked alongside road drunk \\
\hline 5. & Walked alongside road after dagga use \\
\hline 6. & Gambled \\
\hline 7. & Carried weapon \\
\hline 8. & Carried a gun \\
\hline 9. & Used compass as weapon \\
\hline 10. & Threatened others \\
\hline 11. & Was involved in fight \\
\hline 12. & Slapped partner \\
\hline 13. & Forced partner into sex \\
\hline 14. & Attempted suicide \\
\hline 15. & Days smoked \\
\hline 16. & Cigarettes smoked per day \\
\hline 17. & Used snuff \\
\hline 18. & Drank alcohol \\
\hline 19. & Drank one in last month \\
\hline 20. & Drank five drinks in a row in last month \\
\hline 21. & Used dagga \\
\hline 22. & Smoked dagga in last month \\
\hline 23. & Used inhalants \\
\hline 24. & Used prescription drugs to get high \\
\hline 25. & $\begin{array}{l}\text { Had sexual intercourse - how does having sex classify as risk } \\
\text { behaviour - should it not be having sex without protection? }\end{array}$ \\
\hline 26. & Had more than one partner last 3 months \\
\hline 27. & Was high last time had sex \\
\hline 28. & Never used a condom \\
\hline 29. & Did not use birth control measures \\
\hline 30. & Had an abortion \\
\hline 31. & Did nothing about weight \\
\hline 32. & Used unhealthy weight control strategies \\
\hline 33. & Did not do high intensity exercise last week \\
\hline 34. & Did not do low intensity exercise last week \\
\hline 35. & Spent 2 hours in sedentary behaviour \\
\hline
\end{tabular}

drunk. However, other lifetime behaviours were included due to their clinical relevance and likelihood to recur, such as addictive behaviours. A total of 35 behaviours were selected as depicted in Table 1 .

Eleven clusters, shown in Table II were created based on the associations derived from the Chi-square test and literature.

Table II: Behaviour clusters

\begin{tabular}{|c|c|c|}
\hline Cluster & Co-occurring behaviours & $\begin{array}{l}\text { Number of } \\
\text { participants } \\
\text { engaged in } \\
\text { behaviours } \\
\text { concurrently }\end{array}$ \\
\hline Cluster One & $\begin{array}{l}\text { Did not use seat belt when driving } \\
\text { Did not use seat belt when driven } \\
\text { Gambled } \\
\text { Drank alcohol in lifetime }\end{array}$ & Total $=37$ \\
\hline Cluster Two & $\begin{array}{l}\text { Drove drunk } \\
\text { Drank alcohol in lifetime } \\
\text { Had sexual intercourse } \\
\text { Drank one in past month } \\
\text { Days smoked } \\
\text { Had multiple sexual partners in last } \\
3 \text { months }\end{array}$ & Total $=9$ \\
\hline Cluster Three & $\begin{array}{l}\text { Days smoked } \\
\text { Drank alcohol in lifetime } \\
\text { Had sexual intercourse } \\
\text { Forced someone into sex } \\
\text { Binge drunk in past month } \\
\text { Attempted suicide }\end{array}$ & Total $=2$ \\
\hline Cluster Four & $\begin{array}{l}\text { Drank alcohol in lifetime } \\
\text { Drank one in past month } \\
\text { Binge drunk } \\
\text { Cigarettes smoked per day } \\
\text { Fought }\end{array}$ & Total $=31$ \\
\hline Cluster Five & $\begin{array}{l}\text { Drank alcohol in lifetime } \\
\text { Binge drunk } \\
\text { Smoked dagga in lifetime } \\
\text { Smoked dagga last month } \\
\text { Number of Days smoked } \\
\text { Drank one in the last month }\end{array}$ & Total $=29$ \\
\hline Cluster Six & $\begin{array}{l}\text { Used inhalants } \\
\text { Used prescription drugs to get } \\
\text { high } \\
\text { Drank alcohol in lifetime } \\
\text { Binge drunk } \\
\text { Smoked dagga in lifetime } \\
\text { Smoked dagga last month }\end{array}$ & Total $=2$ \\
\hline Cluster Seven & $\begin{array}{l}\text { Had sexual intercourse } \\
\text { Did not use condoms } \\
\text { Used no birth control method } \\
\text { Binge drunk } \\
\text { Drank alcohol in lifetime } \\
\text { Had multiple sexual partners in last } \\
3 \text { months }\end{array}$ & Total $=1$ \\
\hline Cluster Eight & $\begin{array}{l}\text { Walked alongside road drunk } \\
\text { Drank alcohol in lifetime } \\
\text { Walked alongside road after dagga } \\
\text { use } \\
\text { Smoked dagga in lifetime }\end{array}$ & Total $=35$ \\
\hline Cluster Nine & $\begin{array}{l}\text { Carried a weapon } \\
\text { Fought } \\
\text { Used mathematical compass as } \\
\text { weapon } \\
\text { Threatened another person } \\
\text { Slapped partner }\end{array}$ & Total $=13$ \\
\hline
\end{tabular}

..... Table II continued on page 30 
..... Table II continued from page 29

\begin{tabular}{|l|l|c|}
\hline Cluster Ten & $\begin{array}{l}\text { Carried a weapon } \\
\text { Carried a gun } \\
\text { Threatened another person }\end{array}$ & Total= I3 \\
\hline Cluster Eleven & $\begin{array}{l}\text { Weight plan } \\
\text { Did not engage in high intensity } \\
\text { exercise } \\
\text { Did not engage in low intensity } \\
\text { exercise } \\
\text { Engaged in sedentary behaviour } \\
\text { for } 2 \text { or more hours a day } \\
\text { Drank alcohol in lifetime }\end{array}$ & \\
\hline
\end{tabular}

\section{Ethics}

Ethical approval was obtained from the University of Cape Town (FHS HREC REF: 075/20 I0). To gain access to the learners, permission was requested and obtained from the Ministry of Education and Training through the office of the Chief Inspectorate- Secondary and the Principals of the selected schools.

The Sesotho version of the parent consent forms and information sheets were issued and data collection appointments set. The majority of the learners did not return the consent forms while some parents declined reducing the potential number of participants. The principals indicated that they were regarded as legal guardians of the learners while at school. Therefore, they deemed it unnecessary to seek parental consent. However, due to the requirements of the university parental consent was sought. The Sesotho version of information sheets and assent forms were given to the learners. Learners who did not give assent, or were denied parental consent or those who were absent on the day of data collection were excluded from the study.

\section{FINDINGS}

Tobacco use was analysed and reported using gender and age of initiation. In accordance with the objective of this paper the findings presented will focus on tobacco use amongst school going adolescents, showing the extent and nature of use. In this study, tobacco use referred to smoking cigarettes or rolled tobacco and using snuff as these are the most prominent methods of use among youth in Lesotho. Tobacco is neither grown nor packaged in Lesotho, therefore tobacco products are imported ${ }^{43}$, but the products remain easily accessible to adolescents and preteens. Frequencies of tobacco use are illustrated in Table III below.

Smoking was the most predominant form of tobacco use, particularly among males, as depicted in Table III below. 15\% of the participants reported tobacco use as current occupational performance, with $12.2 \%$ admitting to smoking and $2.8 \%$ using snuff on a number of days per month. The age of initiation of smoking was used to establish the percentage of participants who had smoked in a lifetime, regardless of whether they had stopped or not, as captured in Table IV below.

$19.6 \%(\mathrm{~N}=220)$ of the participants had smoked in a lifetime. In terms of gender distribution, $25.1 \%(\mathrm{~N}=42)$ of the early initiators were female and close to three quarters $(74.9 \%, N=125)$ were male. Those participants who started using tobacco at 8 years of age or younger, accounted for $6.8 \%$ of those who had smoked in a lifetime. Smoking among females is frowned upon in Lesotho; perhaps contributing to the smaller percentage of girls that reported to have smoked. The use of snuff is perceived to be an occupation of adulthood or old age and more common among females than males, hence use of snuff was reported by a small percentage of participants.

Tobacco use among 13-15 year old learners in Lesotho was studied in 2002 and 2008 using the Global Youth Tobacco Survey (GYTS). The findings in 2008 showed an overall smoking prevalence of $22.3 \%$ and current tobacco use was reported by $10.1 \%$ of the participants ${ }^{43}$. In this study tobacco use constituted current occupational performance for $15 \%$ of the participants and almost one in five learners (19.6\%) had smoked in a lifetime. Current use for this study was $5 \%$ higher than the national prevalence among 13-I5year olds. This could be due to the higher age bracket applied in this study and the environment of the city of Maseru. The environment of Maseru presses for certain behaviours associated with lifestyles modelled as desirable.

Table III: Percentages of participants who used tobacco

\begin{tabular}{|l|c|c|c|}
\hline Risk behaviour & $\begin{array}{c}\text { \% of male participants } \\
\mathbf{( N = 5 5 9 )}\end{array}$ & $\begin{array}{c}\text { \% of female participants } \\
\mathbf{( N = 5 6 2 )}\end{array}$ & $\begin{array}{c}\text { \% of participants } \\
\text { (N= I I 2 I) engaged in } \\
\text { behaviour }\end{array}$ \\
\hline Smoked in a lifetime & 15.4 & 4.2 & 19.6 \\
\hline Smoked between I and 30 days in past 30 days & 19.9 & 4.5 & 12.2 \\
\hline Smoked at school in past 30 days & 6.6 & 0.9 & 3.8 \\
\hline Used snuff between I and 30 days in past 30 days & 2.2 & 3.4 & 2.8 \\
\hline Used snuff at school in past 30 days & 0.5 & 1.8 & 1.2 \\
\hline Passive smoking in past 7 days & 61.6 & 53.8 & 57.7 \\
\hline Have a smoking guardian & 71 & 72.2 & 71.6 \\
\hline Did not try to stop smoking & 3.4 & 0.7 & 2.1 \\
\hline
\end{tabular}

Table IV: Age of onset

\begin{tabular}{|l|c|c|c|}
\hline Age of onset & Number of male participants & Number of female participants & Total \\
\hline Never smoked & 385 & 515 & 900 \\
\hline$<8$ years old & 31 & 14 & 45 \\
\hline 9-10 years old & 52 & 14 & 66 \\
\hline II-12 years old & 42 & 14 & 56 \\
\hline I3-14 years old & 21 & 3 & 24 \\
\hline I5-16 years old & 13 & 1 & 14 \\
\hline I7 and older & 14 & I & 15 \\
\hline TOTAL & 558 & 562 & 1120 \\
\hline
\end{tabular}


Despite the lower lifetime prevalence of smoking (19.6\%) among the participants as compared to the US, where the overall prevalence in having smoked was $46.3 \%{ }^{44}$ and $29.5 \%$ for South Africa $^{45}$ the high percentage of early initiators is a grave concern. More than one in five $(24.1 \%)$ of those participants who had smoked in a lifetime had started before the age of I 3 as compared to only $10.7 \%$ in the US ${ }^{44}$. In South Africa $6.8 \%$ of the smoking learners initiated before the age of $10^{45}$. This could suggest that learners in Lesotho are more likely to suffer long term consequences associated with tobacco use as they initiate tobacco use early.

Risk behaviours often co-occur and the consequences of concurrent engagement can be severe. Using tobacco could also expose the learner to other substances or other risk behaviours. A significant association was found between smoking cigarettes or rolled tobacco and alcohol and dagga use $(p=0.00)$. An association was also established between smoking and gambling $(p=0.00)$. The nature of the associations requires further exploration as some may be causal and others may just increase the chances of participation in an additional risk behaviour. In this study the association showed co-occurrence; those that smoked also used alcohol or dagga or gambled.

$3.8 \%$ reported smoking at school. The risk associated with smoking at school was the likely exposure of others to second hand smoke. Although this (3.8\%) appears to be a small percentage, it is considerable given the consequences of second hand smoke. More than half of the participants were exposed to second hand smoke $(57.7 \%)$. Although alarming, this was not surprising, given that $71.6 \%$ of the participants' guardians smoked. Therefore, participants were likely to be exposed to second hand smoke at home or when with their guardians $(p=0.00)$, at school and on the way to and from school, thereby increasing the risk of contracting illnesses associated with passive smoking.

\section{Concurrent engagement in risk behaviours}

Concurrence in this paper refers to current engagement in multiple risk behaviours. Less than half $(41.4 \%)$ of the participants participated in six or more risk behaviours concurrently and $55.9 \%$ engaged in between one and five risk behaviours. $2.7 \%$ reported not taking part in any form of risk behaviour. Concurrent engagement in risk behaviours is a concern for occupational therapy as substance use related behaviours were the most prevalent and a strong association between these and tobacco use was found.

Tobacco use dominated clusters with the most number of participants engaging in multiple risk behaviours as depicted in Table IV. However, the analysis was not intended to be exhaustive, rather it focused on behaviours that have the most concerning consequences on health and well-being, hence the reported clusters represented only $15.2 \%$ of the sample. The highest number of behaviours participated in was 21 , and 3 male participants engaged in these behaviours. Table $V$ below presents clusters of behaviours that were found to co-exist, with tobacco use being the common denominator. A more detailed account of other clusters may be found in Ramafikeng ${ }^{37}$.

Tobacco use occurred concurrently with behaviours such as use of other substances, driving under the influence of alcohol, aggressive behaviours such as fighting, and engaging in sexual intercourse with multiple partners. This raises concern with regards to the potential negative consequences on health of such a repertoire.

\section{DISCUSSION}

Literature shows that tobacco use as previous and current occupational performance adversely impact performance in other occupational performance areas, particularly learning as it affects cognitive ability. A study in China found that smoking one cigarette per day reduced learners' mathematical abilities ${ }^{46}$. This may have been due to biological alterations that result in reduced learning ability; nicotine results in damage to the brain and limits cognitive abilities ${ }^{47}$ resulting in poorer academic performance. Learners in this study are also susceptible to poor academic performance due to tobacco use.

In addition to direct impact on occupational performance in various areas, the concurrent existence of tobacco use with other risk behaviours poses a threat to health and well-being. This co-occurrence places high school learners at a higher risk of experiencing the burden of disease and injury. For example, the co-occurrence of behaviours in Cluster three predisposes learners to substance dependence and the risk of contracting sexually transmitted diseases. A country, such as Lesotho and many others, already confronted with extreme poverty, food shortage and HIV/ AIDS cannot ignore the threat to health and wellbeing as a consequence of these clusters of risk behaviours. This threat impacts the youth; the most productive age group that has to contribute to the economy of countries.

Lesotho envisions a healthy human resource base by the year $2020^{48}$ and this could be threatened by current trends in tobacco use among other burdens of disease. Those who initiate tobacco use at a young age are at a higher risk of ill health. In this study, about $24.1 \%$ of those who had smoked in a lifetime started before the age of I 3 with some $(6.8 \%)$ starting as early as 8 years or younger. The long term physical and psychological consequences of tobacco use are undesirable and potentially life threatening and early initiators are at a higher risk given the prolonged use. A study conducted among adolescent girls showed that girls who initiated smoking early we more likely to also engage in other health risk behaviours such as alcohol and marijuana use as well as having unprotected

Table V: Behaviour clusters concurrent with tobacco use

\begin{tabular}{|l|l|l|}
\hline Cluster & Co-occurring behaviours & Number of participants engaged in behaviours concurrently \\
\hline Cluster One & $\begin{array}{l}\text { Cigarettes smoked per day } \\
\text { Drank alcohol in lifetime } \\
\text { Drank in past month } \\
\text { Binge drunk } \\
\text { Fought }\end{array}$ & Total=31 \\
\hline Cluster Two & $\begin{array}{l}\text { Days smoked } \\
\text { Drank alcohol in lifetime } \\
\text { Binge drunk } \\
\text { Smoked dagga in lifetime } \\
\text { Smoked dagga last month } \\
\text { Drank in the past month }\end{array}$ & Total $=29$ \\
\hline Cluster Three & $\begin{array}{l}\text { Days smoked } \\
\text { Drove drunk } \\
\text { Drank alcohol in lifetime } \\
\text { Had sexual intercourse } \\
\text { Drank in past month } \\
\text { Had multiple sexual partners in last 3 months }\end{array}$ & \\
\hline
\end{tabular}


sex $^{49}$. This indicates that the age of initiation of tobacco use could be associated with a higher incidence of co-occurring behaviours.

The age of initiation of tobacco use and other substances has been associated with impaired role performance, increased morbidity and mortality among youth and in adulthood, given the strong likelihood of substance dependence and abuse. Occupational therapists need to recognise tobacco use as within their scope of practice, therefore start designing intervention directed at curbing tobacco use and delaying the age of initiation.

\section{Intervention}

There are various intervention plans that have been drawn up to curb tobacco use. For instance, Lesotho has signed the World Health Organisation Framework Convention on Tobacco Control ${ }^{50}$; however there are no laws or policies in place that control the selling, use and advertising of tobacco products ${ }^{43}$. This creates an opportunity for the profession of occupational therapy in Lesotho to contribute to the relevant development of policies and measures for tobacco control as well as intervention aimed at cessation and prevention of use. Given the likely impact of tobacco use on the Lesotho's vision for the year 2020, there is an urgent need for among others measures that control access to and use of tobacco.

Reported interventions and measures aimed at delaying the age of initiation of tobacco are presented by Pierce et al ${ }^{51: 260}$ as including "school programmes, increasing the price of tobacco through excise tax increases, large graphic warning labels on packages, restricting the tobacco industry's ability to advertise, tobacco control mass media programmes, smoke-free policies and restricting the ability of minors from purchasing tobacco products". Although there is no current policy or legislature on tobacco control in Lesotho, health facilities and schools have been declared as smoke free zones ${ }^{43}$. There are also anti-smoking clubs in schools that are members of the Lesotho Network on Anti-Smoking and their role is to discourage promotion and use of tobacco in schools, therefore making schools, smoke free zones. This may have contributed to the lower prevalence of smoking at school (3.8\%). However, without legislation some schools may not feel obliged to abide by the declaration. This shows that for effective control, the approach to tobacco control and prevention of use has to be comprehensive using multiple strategies ${ }^{51}$. An example of a successful programme in reducing smoking initiation was implemented in California and the goal was denormalisation of tobacco in an entire community ${ }^{52}$. This highlights the role of the community as an important factor in tobacco use related intervention, therefore it shifts the focus from the youth and children alone to everyone.

Parents and guardians have a significant role to play in discouraging tobacco use among children and youth, because their attitudes towards tobacco use tend to influence use among youth and children. For instance, in some societies such as the US ${ }^{53}$, the fear of health consequences associated with second-hand smoke may have influenced a trend towards smoker-related stigmatisation, where people generally avoid spending time with the smoker. In this study, more than half $(54.8 \%)$ of the participants were exposed to second-hand smoke in the past 30 days and $71.6 \%$ of the participants had a parent or guardian that smoked. Given the significant association $(p=0.03)$ established between smoking on a number of days per month and having a guardian that smokes, it could be deduced that exposure to a smoking guardian may have had an impact on the participant's use of tobacco.

Epidemics such as tobacco use require population level interventions and health promotion is one approach that could be adopted to deliver services at this level. An occupation-focused health promotion approach suggests that occupation is at the core of intervention. Wilcock 12:282 defines this approach as "the application of science to prevent illness including occupational illnesses, accidents and disability to prolong quality of life for all through advocacy, mediation and occupation-based programs, enabling people to do, be and become according to their needs." By implementing an occupation- based health promotion approach, occupational therapists can play a significant role in preventing tobacco use and denormalising tobacco use amongst communities using occupations. For instance, occupational therapists could collaborate with communities to explore participation in other occupations instead of tobacco use.

Interventions where occupational therapists have been instrumental in addressing public health issues such as obesity could be used as a point of reference for designing intervention for tobacco use. For example, strategies such as education, adaptations to the environment and introducing and adapting occupations guided by a health promotion approach have been found to be effective in reducing the impact of obesity ${ }^{36}$. In addition, as an addictive substance, intervention for tobacco use could follow similar principles to intervention designed for other addictive substances even though the impact on activities of daily living may manifest differently from that of other substances. Rojo-Mota et $\mathrm{al}^{54}$, suggested that functional rehabilitation should be a fundamental component of the treatment of tobacco use and occupational therapists are equipped with the skills for improving function in daily activities. Intervention must also be reconceptualised to target multiple risk behaviours rather than be directed at single behaviours. A systematic review conducted by Hale et al on effective interventions for reducing multiple health risk behaviours in adolescence highlighted that "targeting multiple risk behaviours simultaneously is more effective and efficient than targeting single risk behaviours" $32: 19$. This integrated approach is what is needed for the participants in this study rather than the single behaviour approach being used, where for instance there are prevention as they also engaged in co-occurring behaviours. For example, in the design on intervention for and addressing substance use, this could include tobacco use.

\section{CONCLUSION}

It is evident from the findings that given the age of initiation and current reported use, tobacco use is best defined as a paediatric public health challenge. Occupational therapists should be alert to this public health concern as early onset of tobacco user has implications for the physical, psychological and the occupational wellbeing of the individual. Initiating tobacco use at an early age has also been found to be a predictor of co-occurring behaviours and the consequences thereof. Design of intervention aimed at delaying initiation of tobacco use would be more beneficial. Often when occupational therapy service users report tobacco user, this is classified as an unhealthy habit that is often not considered when planning intervention. This paper advocates for occupational therapy contribution in intervention aimed at cessation and prevention of tobacco use, particularly among children and youth.

This paper has highlighted that occupational science and occupational therapy have a contribution to make to the way in which this pandemic is addressed. However, further research, exploring the effects of tobacco on other occupational performance areas, particularly for adolescents is urgently needed. Tobacco use is a public health emergency and a paediatric illness that occupational therapists can contribute to using occupation-based cessation and prevention interventions.

At a macro level, occupational therapists, adopting an occupational perspective can contribute to public policy on tobacco control initiatives.

\section{Strengths and limitations}

The strength of this study is that it was ground-breaking, as a study of this nature had previously not been conducted in Lesotho. However, there were limitations. Gaining consent from the parents was a challenge. This resulted in the process of data collection being drawn out while waiting for consent to be granted. In instances where learners were 18 years and older, they were asked to give consent. 
Honesty and accuracy might have been compromised for data from two schools, because the classes were overcrowded and learners had to share desks, thereby maybe influencing each other's responses. However, the integrity of all the data collected was not compromised as this only happened in two schools.

Another limitation could have been self-reporting bias. To reduce this, emphasis was put on anonymity, voluntary participation and honesty in reporting. In addition, school personnel were not present in the room when participants were filling in the survey.

A possible source of errors could have been the modifications in the questionnaire as a result of not testing for reliability and validity. It is therefore a recommendation for the future use of the tool that it be tested for reliability and validity.

\section{ACKNOWLEDGMENTS}

$\leftrightarrow$ Acknowledgements to the National Manpower Development Secretariat (NMDS) of the Government of Lesotho for fully funding my Masters' degree studies.

$\leftrightarrow$ Acknowledgements to Professor Seyi Ladele Amosun for funding the printing of the questionnaire.

* Acknowledgements to Shanali Govender for editing and the members of the Writing Circle; Gregory and Nicole for your feedback and assistance in reviewing this article.

* Acknowledgements to the Educational Development Unit and the University of Cape Town Research and Innovation office for funding a Writer's Workshop where the article was reviewed by Associate Professor Theresa Lorenzo and Richard Jodi.

\section{DECLARATION OF INTEREST}

The authors report no conflicts of interest. The authors alone are responsible for the content and writing of the paper.

\section{REFERENCES}

I. Al-lbrahim MS, Gross, JY. Tobacco Use. In: Walker HK, Hall WD, Hurst JW (eds). Clinical Methods: The History, Physical, and Laboratory Examinations.3rd edition. Boston: Butterworths, 1990.

2. Muttappallymyalil J, Divakaran B, Sreedharan J, Thomas T, Haran JC, Thanzeel M. Prevalence of Tobacco Use Among Adolescents in India. Asian Pacific J Cancer Prev. 20 I 2; I3: 537I-5374. http://dx.doi.org/I0.73 I4/APJCP.2012.13.1 I.537I.

3. Strine TW, Okoro CA, Chapman DP, Balluz LS, Ford ES, Ajani UA, Mokdad $\mathrm{AH}$. Health-related Quality of Life and health risk behaviours among smokers. American Journal of Preventative Medicine. 2005;28(2): 182-187.

4. Sim TH. Technical report- Tobacco as a substance of abuse. Pediatrics 2009; I 24(5):e l 045-e l 053. Retrieved from www.pediatrics.org/cgi/ doi/I0.I542/peds.2009-2I 2 I (24 February 20I0).

5. Reddy SP, Panday S, Swart D, Jinabhai CC, Amosun SL, James S, Monyeki KD, Stevens G, Morejele N, Kambaran NS, Omardien RG, Van den Borne HW. Umthenthe Uhlaba Usamila - The South African Youth Risk Behaviour Survey 2002. Cape Town: South African Medical Research Council. 2003.

6. Kiepek N, Magalháes L. Addictions and impulse-control disorders as occupation: A selected literature review and synthesis. Journal of Occupational Science. 20I I; 18:254-276. I0.1080/I442759|.20II.58I628.

7. Fisher AG, Griswold LA. Performance skills: Implementing performance analyses to evaluate quality of occupational performance. Willard and Spackman's occupational therapy. 2014: 249-64.

8. Dhavan P, Stigler MH, Perry CL, Arora M, Reddy KS. Is tobacco use associated with academic failure among government school students in urban India. Journal of School Health. 2010; 80 (I I): 552-560.

9. Chen R, Clifford A, Lang L, Anstey KJ. Is exposure to second hand smoke associated with cognitive parameters of children and adolescents- a systematic literature review. Annals of Epidemiology. 2013; 23(10): 652-66I.

10. Almomani F, Josman N, Al-momani MO, Malkawi SH, Nazzal M, Almahdawi K, Almomani F. Factors related to cognitive functioning among elementary school children. Scandinavian Journal of Occupational Therapy. 2014; 21 (3): 191-198.

II. Macera CA, Aralis HJ, MacGregor JA, Rauh MJ, Han PP, Galarneau MR. Cigarette Smoking, Body Mass Index, and Physical Fitness Changes Among Male Navy Personnel. Nicotine \& Tobacco Research. 20 I I; I3: 965-97I. http://doi.org/ 10. 1093/ntr/ntr I04.

12. Wilcock AA. An occupational perspective of health (2nd ed.). Thorofare, NJ: Slack. 2006.

13. Luck K, Beagan B. Occupational Transition of Smoking Cessation in Women: "You're Restructuring Your Whole Life", Journal of Occupational Scienc. 2014. http://doi.org/10.1080/|4427591.20|4.8874/8.

14. Wolsko C, Mohatt GV, Lardon C, Burket R. Smoking, chewing, and cultural identity: Prevalence and correlates of tobacco use among the Yup'ik - The Center for Alaska Native Health Research (CANHR) study. Cultural Diversity and Ethnic Minority Psychology. 2009; I5 : I65-172. http://doi.org/10.1037/a0015323.

I5. Stjerna M, Lauritzen SO, Tillgren P. "Social thinking” and cultural images: teenagers' notions of tobacco use. Social Science \& Medicine. 2004; 59: 573-583. http://doi.org/10.1016/j.socscimed.2003.II.003.

16. Van Der Rijt GAJ, Haenens LSJ, van Straten P. Smoking and other substance use as distinct features of teenage subcultures. Journal of Adolescent Health. 2002; 31: 433-435. http://dx.doi.org/10.1016/S I054-I39X(02)00394-4.

17. World Health Organization. WHO REPORT On The Global Tobacco Epidemic, 2013 Enforcing bans on tobacco advertising, promotion and sponsorship. Executive summary. Switzerland: WHO Press. 2013.

18. WHO. IO facts on second-hand smoke. Retrieved from http://www. who.int/features/factfiles/tobacco/en/ 2009.

19. Hara M, Inoue M, Shimazu T, Yamamoto S, Tsugane S. The association between cancer risk and age at onset of smoking in Japanese. J Epidemiol. 2010; 20(2): I28- 135.

20. Garbin U, Pasini AF, Stranieri C, Cominacini M, Pasini A, Manfro S, Lugoboni F, Mozzini C, Guidi G, Faccini G, Cominacini L. Cigarette Smoking Blocks the Protective Expression of Nrf2/ARE Pathway in Peripheral Mononuclear Cells of Young Heavy Smokers Favouring Inflammation. PLoS ONE 2009;4(I 2): e8225. Retrieved from www. plosone.org.

21. Beaglehole R, Petersen PE. Global facts on tobacco or oral health. Retrieved from www.who.int/oral_health 2005.

22. Huxley RR, Woodward M. Cigarette smoking as a risk factor for coronary heart disease in women compared with men: a systematic review and meta-analysis of prospective cohort studies. Lancet. 20II; 378: 1297-305. http://doi.org/10.10 I6/S0I40-6736(I I)6078I-2.

23. Husky MM, Mazure CM, Paliwal P, McKee SA. Gender differences in the comorbidity of smoking behavior and major depression. Drug Alcohol Depend. 2008; 93: I76-I79.

http://doi.org/10.1016/j.drugalcdep.2007.07.015.

24. Goodwin RD, Lewinsohn PM, Seeley JR. Cigarette smoking and panic attacks among young adults in the community: The role of parental smoking and anxiety disorders. Biological Psychiatry. 2005; 5: 686-693.

25. Pratt LA, Brody DJ. Depression and smoking in the U.S. household population aged 20 and over, 2005-2008. NCHS Data Brief 2010; 34: I-8. Retrieved from http://www.cdc.gov/nchs/data/databriefs/ db34.htm.

26. Scott TJL, Heil SH, Higgins ST, Badger GJ, Bernstein IM. Depressive symptoms predict smoking status among pregnant women. Addictive Behaviors. 2009; 34: 705-708. http://doi.org//0.1016/j.addbeh.2009.04.003.

27. Jamal M, Van der Does AJW, Penninx BWJH, Cuijpers P. Age at Smoking Onset and the Onset of Depression and Anxiety Disorders. Nicotine \& Tobacco Research. 20I I; I3(9): 809-8I9.

28. Mathers M, Toumbourou JW, Catalano RF, Williams J, Patton GC. Consequences of youth tobacco use: a review of prospective behavioural studies. Addiction. 2006; I01: 948-958. http://doi.org/I0. I I I I/j. I360-0443.2006.01438.x

29. Hanna EZ, Yi H, Dufour MC, Whitmore CC. The relationship of early-onset regular smoking to alcohol use, depression, illicit drug use, and other risky behaviors during early adolescence: Results from the youth supplement to the Third National Health and Nutrition 
Examination Survey. Journal of Substance Abuse. 200 I; 13: 265-282. http://doi.org/I0.1016/s0899-3289(0I)00077-3.

30. Asante KO, Meyer-Weitz A, Petersen I. Mental Hwalth and Health Risk Behaviours of Homeless Adolescents and Youth: A Mixed Methods Study. Child Youth Care Forum. 2016; 45: 433-449.

31. Mustanski B, Byck GR,, Dymnicki A, Sterrett E, Henry D, Bolland J. Trajectories of multiple adolescent health risk behavors in lowincome African American population. Developmental Psychopathology. 2013. http://doi.org//0.1017/S09545794I3000436.

32. Hale DR, Fitzgerald-Yau N, Viner RM. A systematic review of effective interventions for reducing multiple health risk behaviors in adolescence. American journal of public health. 2014 May; 104(5): el9-4I.

33. Hammell WK. Contesting assumptions in occupational therapy. In: Molineux CM, Supyk-Mellson J eds. Occupational therapy and physical dysfunction. Edinburgh: Churchill Livingstone. 20 I0: 4I-54

34. Kiepek N, Phelan SK, Magalha es L. Introducing a critical analysis of the figured world of occupation. Journal of Occupational Science. 2013. http://doi.org/10.1080/I442759I.2013.8I6998.

35. Twinley R. The dark side of occupation: A concept for consideration. Australian Occupational Therapy Journal 20I 3; 60:30I-303. http://doi.org/I0.1 III//440-1630.12026.

36. Haracz K, Ryan S, Hazelton M, James C. Occupational therapy and obesity: An integrative literature review. Australian Occupational Therapy Journal. 20 I3; Oct; 60(5): 356-65. http://doi.org//0.1 I I I/I440-1630.12063.

37. Ramafikeng $M$. The prevalence of health risk behaviours among high school learners in the city of Maseru, Lesotho. (Unpublished Master's thesis). University of Cape Town: Cape Town. 2010.

38. Bureau of Statistics [Lesotho]. Lesotho Demographic Survey, 20 I I, Vol I. Maseru, Lesotho: The Bureau of Statistics. Retrieved from http://www.bos.gov.ls/ 2013.

39. Bureau of Statistics [Lesotho]. Statistical Yearbook 2008. Retrieved from http://ls.china-embassy.org/eng/sgdt/ P0201007I5I89344525549.pdf.

40. Ministry of Education and Training. Kingdom of Lesotho Education Sector Strategic Plan 2005-20 I5. Maseru: Government of Lesotho. 2005.

4I. Centers for Disease Control and Prevention. MMWR. Surveillance Summaries. 2008; 57(SS-4): -36.

42. StataCorp. STATA I0.0 Statistics/ Data Analysis [software]. Retrieved from http://www.stata.com 2007.

43. Moremoholo N. The Lesotho Global Youth Tobacco Survey Report (2008). Tobacco Control Policy Implications. Ministry of Health and Social Welfare, Lesotho: Health Education Division. 2008.

44. Centers for Disease Control and Prevention. MMWR. Surveillance Summaries. 20I 59(SS-5): I0-I7.

45. Reddy SP, James S, Sewpaul R, Koopman F, Funani NI, Sifunda S, Josie J, Masuka P, Kambaran NS, Omardien RG. Umthente Uhlaba Usamila - The South African Youth Risk Behaviour Survey 2008. Cape Town: South African Medical Research Council. 2010.

46. Zhao M, Konishi Y, Glewwe PP. Does smoking affect schooling? Evidence from teenagers in rural China. Journal of Health Economics 20I2 3I (4):584-598. http://dx.doi.org/10.1016/j.jhealeco.2012.04.005

47. Jacobsen LK, Krystal JH, Mencl WE, Westerveld M, Frost SJ, Pugh $\mathrm{KR}$. Effects of smoking and smoking abstinence on cognition in adolescent tobacco smokers. Biological Psychiatry. 2005 57(I): 56-66.

48. National Vision Document. Retrieved from http://www.lesotho.gov. Is/documents/National_Vision_Document_Final.pdf 2004.

49. DiNapoli PP. Early initiation of tobacco use in adolescent girls: key sociostructural influences. Appl Nurs Res. 2009; 22: 126-32. http://doi.org/10.1016/j.apnr.2007.07.00I.

50. WHO FCTC. WHO Framework Convention on Tobacco Control. Geneva Switzerland: World Health Organisation. 2003.

5I. Pierce JP, White V M, Emery SL. What public health strategies are needed to reduce smoking initiation? Tobacco Control. 20 I2; 2I: 258e264. http://doi.org/I0.I I 36/tobaccocontrol-20 I I-050359.

52. Bal DG, Kizer KW, Felten PG, et al. Reducing tobacco consumption in California. Development of a statewide anti-tobacco use campaign. JAMA. 1990; 264: 1570e4.

53. Stuber J, Galea S, Link BG. Smoking and the emergence of a stigmatized social status. Social Science \& Medicine. 2008; 67: 420-430. http://doi.org/I0.1016/j.socscimed.2008.03.010.

54. Rojo-Mota G, Pedrero-Pérez EJ, Ruiz-Sánchez de León JM, Miangolarra Page JC. Assessment of motor and process skills in daily life activities of treated substance addicts. Scandinavian Journal of Occupational Therapy. 20I4; 2I(6): 458-464.

Corresponding Author

Matumo Ramafikeng

mc.ramafikeng@uct.ac.za 


\section{Appendix}

\section{Lesotho Youth Risk Behaviour Survey - 2010}

\section{Section E: The following questions are about tobacco use}

50. How old were you when you first smoked rolled tobacco (BB) or a cigarette?
A. I have never smoked rolled tobacco or a whole cigarette
B. 8 years old or younger
C. 9 or 10 years old
D. II or 12 years old
E. 13 or 14 years old
F. 15 or 16 years old
G. 17 years old or older

5I. During the past month (30 days), on how many days did you smoke cigarettes or rolled tobacco (BB)?
A. 0 days
B. I or 2 days
C. 3 to 5 days
D. 6 to 9 days
E. 10 to 19 days
F. 20 to 29 days
G. All 30 days

52. During the past month (30 days), on the days you smoked, how many cigarettes did you smoke per day?
A. I did not smoke cigarettes during the past 30 days
B. Less than I cigarette per day
C. I cigarette per day
D. 2 to 5 cigarettes per day
E. 6 to 10 cigarettes per day
F. II to 20 cigarettes per day
G. More than 20 cigarettes per day

53. During the past month ( 30 days), how did you usually get your own cigarettes? (Choose only one answer.)

A. I did not smoke cigarettes during the past 30 days

B. I bought them in a store, supermarket, spaza, petrol station or from a street vendor

C. I asked someone who smokes

D. I gave someone else money to buy them for me

E. I borrowed them from someone else

F. A person 18 years old or older gave them to me

G. I took them from a store or family member

H. I got them some other way

54. During the past $\mathbf{3 0}$ days, on how many days did you smoke cigarettes at school?
A. 0 days
B. I or 2 days
C. 3 to 5 days

D. 6 to 9 days

E. 10 to 19 days

F. 20 to 29 days

G. All 30 days

55. During the past year, have you ever tried to stop smoking?
A. I have never smoked
B. I did not smoke during the past 12 months
C. Yes, I tried to stop smoking
D. No, I did not tried to stop smoking

56. During the past month ( 30 days), on how many days did you use snuff?
A. 0 days
B. I or 2 days
C. 3 to 5 days
D. 6 to 9 days
E. 10 to 19 days
F. 20 to 29 days
G. All 30 days

57. During the past 30 days, on how many days did you use snuff at school?
A. 0 days
B. I or 2 days
C. 3 to 5 days
D. 6 to 9 days
E. 10 to 19 days
F. 20 to 29 days
G. All 30 days

58. During the past week (7days), how many days have people smoked in your presence?
A. 0 days
B. I to 2 days
C. 3 to 4 days
D. 5 to 6 days
E. 7 days

59. Do your parents/guardians smoke?
A. Both my parents / guardians do not smoke
B. Both my parents / guardians smoke
C. Only my father / male guardian smokes
D. Only my mother / female guardian smokes
E. I don't know 